\title{
RESEARCH
}

Open Access

\section{Descriptive epidemiology of physical activity energy expenditure in UK adults (The Fenland study)}

Tim Lindsay, Kate Westgate, Katrien Wijndaele, Stefanie Hollidge, Nicola Kerrison, Nita Forouhi, Simon Griffin, Nick Wareham and Søren Brage* (i)

\begin{abstract}
Background: Physical activity (PA) plays a role in the prevention of a range of diseases including obesity and cardiometabolic disorders. Large population-based descriptive studies of PA, incorporating precise measurement, are needed to understand the relative burden of insufficient PA levels and to inform the tailoring of interventions. Combined heart and movement sensing enables the study of physical activity energy expenditure (PAEE) and intensity distribution. We aimed to describe the sociodemographic correlates of PAEE and moderate-to-vigorous physical activity (MVPA) in UK adults.
\end{abstract}

Methods: The Fenland study is a population-based cohort study of 12,435 adults aged 29-64 years-old in Cambridgeshire, UK. Following individual calibration (treadmill), participants wore a combined heart rate and movement sensor continuously for 6 days in free-living, from which we derived PAEE $\left(\mathrm{k} \cdot \mathrm{day}^{-1} \cdot \mathrm{kg}^{-1}\right)$ and time in MVPA (> $3 \&>4$ METs) in bouts greater than $1 \mathrm{~min}$ and $10 \mathrm{~min}$. Socio-demographic information was self-reported. Stratum-specific summary statistics and multivariable analyses were performed.

Results: Women accumulated a mean (sd) $50(20) \mathrm{kJ} \cdot \mathrm{day}^{-1} \cdot \mathrm{kg}^{-1}$ of PAEE, and 83(67) and 33(39) minutes.day ${ }^{-1}$ of 1-min bouted and 10-min bouted MVPA respectively. By contrast, men recorded $59(23) \mathrm{kJ} \cdot \mathrm{day}^{-1} \cdot \mathrm{kg}^{-1}$, 124(84) and 60(58) minutes.day ${ }^{-1}$. Age and BMI were also important correlates of PA. Association with age was inverse in both sexes, more strongly so for PAEE than MVPA. Obese individuals accumulated less PA than their normal-weight counterparts, whether considering PAEE or allometrically-scaled PAEE $\left(-10 \mathrm{~kJ} \cdot \mathrm{day}^{-1} \cdot \mathrm{kg}^{-1}\right.$ or $-15 \mathrm{~kJ} \cdot \mathrm{day}^{-1} \cdot \mathrm{kg}^{-2 / 3}$ in men). Higher income and manual work were associated with higher PA; manual workers recorded $13-16 \mathrm{~kJ} \cdot \mathrm{kg}^{-1} \cdot$ day $^{-1}$ more PAEE than sedentary counterparts. Overall, $86 \%$ of women and $96 \%$ of men accumulated a daily average of MVPA (> 3 METs) corresponding to $150 \mathrm{~min}$ per week. These values were 49 and $74 \%$ if only considering bouts $>10$ min (15 and 31\% for > 4 METs).

Conclusions: PA varied by age, sex and BMl, and was higher in manual workers and those with higher incomes. Light physical activity was the main driver of PAEE; a component of PA that is currently not quantified as a target in UK guidelines.

Keywords: Physical activity, energy expenditure, sociodemographic, combined sensing

\footnotetext{
* Correspondence: soren.brage@mrc-epid.cam.ac.uk

MRC Epidemiology Unit, University of Cambridge, School of Clinical

Medicine, Institute of Metabolic Science, Cambridge Biomedical Campus, Box

285, Cambridge CB2 OQQ, UK
}

(c) The Author(s). 2019 Open Access This article is distributed under the terms of the Creative Commons Attribution 4.0 International License (http://creativecommons.org/licenses/by/4.0/), which permits unrestricted use, distribution, and reproduction in any medium, provided you give appropriate credit to the original author(s) and the source, provide a link to the Creative Commons license, and indicate if changes were made. The Creative Commons Public Domain Dedication waiver (http://creativecommons.org/publicdomain/zero/1.0/) applies to the data made available in this article, unless otherwise stated. 


\section{Background}

Physical activity (PA) plays an important role in the prevention of a range of diseases including obesity and cardiometabolic disorders [1-3]. It is hence an important behavioural target for public health interventions, and guidelines describing desired levels of PA have been proposed $[4,5]$. In order to assess the population burden of insufficient levels of PA, and develop effective, tailored interventions, it is important to describe physical activity levels and examine the socio-demographic correlates.

Human behaviour occurs across an intensity spectrum ranging from sleep and sedentary behaviour (SS), to light physical activity (LPA), moderate physical activity (MPA) and vigorous physical activity (VPA). Typically, these intensities are grouped according to a metabolic equivalent of task (METs), e.g. LPA considered as 1.5-3 METs, MPA as 3-6 METs, and VPA as greater than 6 METs, although such classification is not universal [6]. Recent updates in physical activity guidelines emphasize the importance of moderate-to-vigorous PA (MVPA) but increasingly recognise the importance of all subcomponents of the entire intensity spectrum [4]. Moreover, the 2018 guidelines for Americans no longer include the requirement for activity to occur in bouts of at least 10-min duration. Whilst other countries may adopt this definition, it is far from universal and the consequences of such reclassification in terms of activity levels in different socio-demographic groups are not well documented with objective measurements in large cohorts.

Objectively measured PAEE of smaller British cohorts has been reported, including a nationally representative sample of children and adults measured with the doubly labelled water method [7]; however, this method can only assess total volume of PAEE, and the sample was too small $(n=770)$ to describe socio-demographic differences. Two other British cohort studies have described PAEE and its underlying intensity distribution, one in adolescents aged 16y and one in older adults aged between 60 and $64 y$, respectively [8, 9]. The descriptive epidemiology of PAEE and intensity in younger to middle-aged UK adults has not yet been reported. To fill this knowledge gap, we used data from the Fenland cohort, an ongoing population-based observational study of 12,435 adults aged 29-64 years of age, residing in Cambridgeshire, UK. We aimed to describe the objectively measured levels of PAEE and underlying intensity patterns by socio-demographic characteristics.

\section{Methods}

\section{Study population}

Participants born between 1950 and 1975 were recruited to the Fenland Study from general practice lists between 2005 and 2015. Exclusion criteria included pregnancy, physician-diagnosed diabetes, inability to walk unaided, psychosis, and terminal illness. In total, 12,435 participants, aged 29-64 years old, were enrolled and attended one of three clinical research facilities (Ely, Cambridge, and Wisbech) after an overnight fast. All participants provided written informed consent and the study was approved by the local ethics committee (NRES Committee - East of England Cambridge Central) and performed in accordance with the Declaration of Helsinki. In addition, approval was granted to compare general practice-held information (age, sex, height, weight, smoking, alcohol consumption, area deprivation score) for participants with the overall eligible sample (under UK Section 251 legislation).

\section{Anthropometry and other clinical measures}

Height was measured with a rigid stadiometer (SECA 240; Seca, Birmingham, UK) and weight was measured in light clothing with calibrated scales (TANITA model BC-418 MA; Tanita, Tokyo, Japan). Seated blood pressure was measured with an automated sphygmomanometer (Omron, 705CP-II) and a 12-lead ECG (Seca CT6i) was obtained during supine rest. Participants were cleared for submaximal exercise testing if blood pressure was <180/110 mmHg, no serious anomalies were observed on the ECG, alongside appropriate responses to medical screening questions and a review of medication (e.g. high-dose betablocker users were excluded from the treadmill test).

\section{Objective physical activity assessment}

Participants were fitted with a combined heart rate and uniaxial movement sensor (Actiheart, CamNtech, Papworth, UK), attached to the chest with standard ECG electrodes [10]. Participants had their heart rate measured continuously during a 6-min supine rest test and then underwent a submaximal treadmill test consisting of 9-min of walking on the flat with increasing speed, 6min walking at increased gradient, and 5-min of jogging on the flat as previously described [11]. Heart rate was measured continuously and the test was terminated when heart rate reached $90 \%$ of age-predicted maximum [12], or had been above $80 \%$ for longer than 2-min, or the participant requested to stop. At the end of the clinical visit, participants were asked to wear the heart rate and movement sensor, initialised to collect data at 1-min resolution, for the following 6 days [10], and to return the monitor by freepost. Participants were advised that the device was waterproof and should be worn continuously, including during showering, water-based activities, and sleeping, whilst continuing with their usual activities. It could be removed to change electrodes, spare sets of which were provided.

Following pre-processing of the free-living heart rate data to eliminate potential noise [13], heart rate was 
individually calibrated using parameters obtained from the treadmill test [11] and combined with acceleration in a branched equation model [14] to calculate instantaneous PAEE $\left(\mathrm{J}^{\circ} \mathrm{kg}^{-1} \cdot \mathrm{min}^{-1}\right)$; this measure of intensity agrees well with intensity measured using indirect calorimetry $[15,16]$. For participants without sufficient treadmill data for individual calibration ( $n=468$ of 12,002), an age-, sex-, and sleeping heart rate (SHR) adjusted group calibration was used, derived on all other participants as follows:

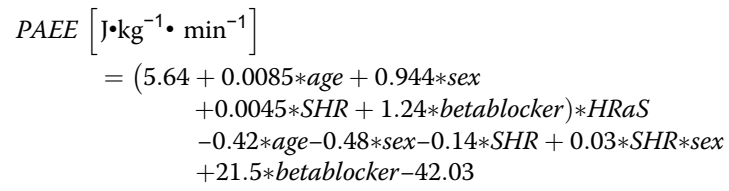

(age in years, sex coded as 1 for men and 0 for women, SHR in beats per minute, heart rate above sleep (HRaS) in beats per minute, and betablocker coded as 0 or 1 if the participant was taking betablocker medication).

Intensity was expressed in standard metabolic equivalents (METs), using $1 \mathrm{MET}=71 \mathrm{~J} \cdot \mathrm{min}^{-1} \cdot \mathrm{kg}^{-1}(\sim 3.5 \mathrm{ml}$ $\left.\mathrm{O}_{2} \cdot \min ^{-1} \cdot \mathrm{kg}^{-1}\right)$.

Segments of data with continuous zero acceleration lasting $\geq 90$ min were classified as 'non-wear' if also accompanied by non-physiological HR data, i.e. consistently high Bayesian error [13]. Average daily PAEE (in $\mathrm{kJ} \cdot \mathrm{day}^{-1} \cdot \mathrm{kg}^{-1}$ ) and time spent at multiple intensity levels (up to $10 \mathrm{METs}$ ) and in at least moderate intensity bouts was summarised, whilst minimising potential diurnal bias by imbalance of wear time [17]. This method has been successfully validated against PAEE from doubly-labelled water in UK men and women [18]. Time and energy spent at specific intensity levels were grouped together and defined as sedentary/sleep (SS), light physical activity (LPA), moderate physical activity (MPA) and vigorous physical activity (VPA). Activity bouts of at least 3 and 4 MET (moderate) intensity were calculated in durations ranging from 1 to 10 mins. For the primary analysis SS was defined as $<1.5$ METs, LPA as 1.5-3 METs, MPA as 3-6 METs, and VPA as $>6$ MET. Sensitivity analyses were conducted using LPA as 1.5-4 METs, MPA as 4-7 METs, and VPA as > 7 METs, and allometrically scaled PAEE (in $\mathrm{kJ} \cdot$ day $^{-1} \cdot \mathrm{kg}^{-2 / 3}$ ) as previously described $[19,20]$.

For the present analysis, participants were excluded $(n=351)$ if they had worn their sensors for $<72 \mathrm{~h}$ overall, or had not worn their sensors for a combined total of at least $8 \mathrm{~h}$ throughout each quadrant of the day. Day quadrants were defined as time blocks between 3 am to $9 \mathrm{am}, 9 \mathrm{am}$ to $3 \mathrm{pm}, 3 \mathrm{pm}$ to $9 \mathrm{pm}$, and $9 \mathrm{pm}$ to $3 \mathrm{am}$, thus expecting $36 \mathrm{~h}$ in each of these for a perfectly balanced and fully compliant 6-day wear. Furthermore, activity records were excluded if they did not measure $0 \mathrm{~m} \cdot \mathrm{s}^{-2}$ at some point (indicating no movement) during the monitoring period to safeguard the analysis from technical accelerometer errors $(n=82)$.

\section{Socio-demographic characteristics}

Socio-demographic and lifestyle behavioural information was collected using self-report. This included age, sex, ethnicity, work-type/status (sedentary, standing, manual, retired, unemployed), marital status (single, married/cohabiting, widowed/separated/divorced), education (compulsory, further - A-level/apprenticeship/sub-degree level, higher - degree level or above), household income level $(<£ 20,000, £ 20,000-£ 40,000,>£ 40,000)$, smoking status (never, former, current) and alcohol intake (units/ week). In addition, location (Cambridge, Ely, Wisbech) and season of physical activity measurement was considered (coded as two orthogonal sine functions; "Winter" peaking at 1 on January 1st and reaching a minimum of -1 on July 1st, and Spring peaking at 1 on April 1st and reaching a minimum of -1 on October 1st).

\section{Statistics}

All analyses were sex-stratified. We report medians (interquartile ranges) or means (standard deviations) for descriptive purposes for continuous variables and proportions for categorical variables. We performed linear test for trend of activity differences for ordinal covariates and likelihood-ratio tests for categorical covariates. We used sex-stratified multivariable linear regression to model the independent associations of activity outcomes with age, BMI, education level, work-type, income, marital status, test site, smoking status, ethnicity, and season of activity measurement. For this analysis, missing data in categorical variables were coded as a separate category.

Using all available information from the general practices, we compared all invited vs all participating by twosample, unpaired t-test for continuous variables and chisquare test for categorical variables. All statistical analyses were performed using Stata/SE version 14.

\section{Results}

A total of 46,024 individuals were invited, of whom 12, 435 (27\% response rate) agreed to participate. General practice information was obtained on 45,043 individuals including 12,145 study participants; one practice could not provide any standard information $(n=180)$, and a few additional participants did not consent to this linkage, had no valid NHS number or their GP surgery information was missing $(n=110)$. Compared to the overall sampling frame, participants were approximately 18 months older, had lower BMI $[0.2$ (men); 0.8 (women) $\mathrm{kg} / \mathrm{m}^{2}$ lower], were less likely to smoke, and had marginally lower deprivation scores. Although there 
was a higher prevalence of alcohol drinkers, participants drank fewer units per week (Additional file 1: Table S1).

Of the 12,435 participants, 12,002 met the combined sensing inclusion criteria for the present analysis, more women $(n=6428)$ than men $(n=5574)$ (Table 1$) .91 \%$ of participants identified as White, with smaller groups of Black, South Asian and East Asian participants. This subsample did not significantly differ from the full Fenland sample, with the exception of men being 0.1 years younger $(p=0.02)$.

Mean (SD) PAEE for women was $50(20) \mathrm{kJ}^{\circ} \mathrm{day}^{-1} \cdot \mathrm{kg}^{-1}$, compared to 59 (23) $\mathrm{kJ}^{\circ} \cdot \mathrm{day}^{-1} \cdot \mathrm{kg}^{-1}$ for men (Table 1). Women recorded an average of 83 (67) minutes per day of MVPA, of which 33 (39) $\mathrm{min} /$ day occurred in bouts of 10min or longer, whereas men recorded 124 (85) and 60 (58) $\mathrm{min} /$ day, respectively. Of note, despite the differences in PAEE and MVPA as measured by combined sensing, women and men did not differ by chest acceleration. Further participant characteristics are listed in Table 1 and univariable analysis by category in Additional file 1: Table S2.

Age and BMI were inversely associated with PAEE, 1min bouted MVPA and 10-min bouted MVPA, with levels of all three outcomes significantly lower in the oldest age group (60-64y) than the youngest age (group 29-34y), and in those classified as obese compared to normal weight participants (Table 2; $p<0.01$ ). Fig. 1 presents box plots (median and IQR) of PAEE by three age categories and three BMI groups $(29-44 \mathrm{y}, 45-54 \mathrm{y}$, 55-64y; normal weight, overweight, obese) and is reflective of the overall age and BMI trends with respect to PAEE and MVPA. In both men and women, PAEE was highest in younger age categories and progressively lower in those 45 years and upwards. PAEE was consistently lower with advancing age, more so than MVPA which was not significantly different in either sex between those in their 30s and 40s, but lower in those in the 6th and 7th decade of life (Table 2). Similarly, those with the lowest BMI recorded the highest levels of PA, with gradually lower levels noted with higher BMI; a trend which was more pronounced in women. Sensitivity analysis conducted with allometrically scaled PAEE confirmed BMI to be inversely associated with PAEE, with differences between normal weight and obese participants preserved (Additional file 1: Table S3). Proportion of week/weekend wear was not associated with PAEE but there was a trend towards those recruited later in the study period of 2005 to 2015 having lower activity levels.

Across the sample, LPA was the primary contributor of energy to total PAEE (59\% in women, $51 \%$ in men), although men accumulated higher levels of MPA and VPA than women (Fig. 2). However, the majority of time was spent asleep or sedentary (70\% women, $69 \%$ men), demonstrating that participants spent a relatively small fraction of the day accumulating most of their PAEE. Women spent almost all their time below 9 METs and men below 11 METS (Additional file 2: Figure S1). Time use demonstrated a similar association with age as for PAEE; time in LPA was lower in older participants, with a reciprocal higher time spent asleep or sedentary. This was accompanied by a commensurate lower PAEE derived from LPA in older participants.

Multivariable analysis (Table 2) showed further associations with PA, including ethnicity, work-type, income, and smoking status. Ethnic minorities tended to be less active than White participants, although the sample sizes of some groups are too small to assess this with certainty. Participants with more physically demanding jobs also had higher activity levels; however retired individuals were more active than those with sedentary occupations. When adjusted for all other socioeconomic variables, this equated to women in manual occupations accumulating $13 \mathrm{~kJ} \cdot$ day $^{-1} \cdot \mathrm{kg}^{-1}$ more PAEE than those in sedentary jobs, and 38 and 18 more minutes of MVPA in bouts of $>1$ min and $>10$ min respectively. In men, corresponding differences were $16 \mathrm{~kJ} \cdot \mathrm{day}^{-1} \cdot \mathrm{kg}^{-1}, 56$ and $29 \mathrm{~min} /$ day.

Education was not significantly associated with PA after adjustment (Table 2). However, there was some indication of higher activity levels in those with higher socio-economic status, more so in men for income level. This picture was mixed as demonstrated by the higher activity in men and trend towards lower activity in women from the Wisbech site, compared to the more affluent Cambridge site. A sex difference was also observed for civil status, in that marriage (current or former) was positively associated with activity in men but tended to be inversely associated in women, compared to single status. Current and former smokers tended to have higher PAEE and MVPA than nonsmokers for both sexes; however, smokers moved less when only considering the accelerometry component (Additional file 1: Tables S2 and S3). Participants who were measured in the summer were more active than those measured in the winter; this difference was twice as big in men as in women, i.e. 20-min and 10-min difference in 1min bouted MVPA between mid-winter and mid-summer.

Overall, compliance with the 2010 UK PA guidelines (as defined by $150 \mathrm{~min}$ of MVPA per week in bouts $>10$ min) was higher in men than in women; $49 \%$ of women and $74 \%$ of men accumulated at least $21.4 \mathrm{~min}$ of MVPA/day (equivalent to meeting the guidelines of 150 min MVPA per week) in bouts lasting 10-min or longer when MVPA was defined as $>3$ METs. Considering this duration target with MVPA $>3$ METs of at least 1-min duration, however, compliance was 86 and 96\%, respectively. Conversely, defining MVPA with the higher 4 METs cut-off naturally resulted in lower absolute levels of MVPA and guideline compliance, as highlighted in 
Table 1 Participant Characteristics. The Fenland Study 2005 to 2015

\begin{tabular}{|c|c|c|c|c|}
\hline & Women & & Men & \\
\hline & $n=6428$ & & $n=5574$ & \\
\hline & N or Mean & $\%$ or sd & N or Mean & $\%$ or sd \\
\hline Age (years) & 48.7 & 7.4 & 48.6 & 7.6 \\
\hline BMI $\left(\mathrm{kg} / \mathrm{m}^{2}\right)$ & 26.5 & 5.3 & 27.3 & 4.1 \\
\hline Ethnicity & & & & \\
\hline White & 5954 & 92.6 & 5165 & 92.7 \\
\hline South Asian & 74 & 1.2 & 75 & 1.4 \\
\hline Black & 30 & 0.5 & 31 & 0.6 \\
\hline East Asian & 44 & 0.7 & 20 & 0.4 \\
\hline Others or unknown & 326 & 5.0 & 283 & 5.1 \\
\hline Education level & & & & \\
\hline Basic & 1442 & 22.4 & 1005 & 18.0 \\
\hline Further & 2923 & 45.5 & 2601 & 46.7 \\
\hline Higher & 2063 & 32.1 & 1968 & 35.3 \\
\hline Work type & & & & \\
\hline Sedentary & 3014 & 46.9 & 2860 & 51.3 \\
\hline Standing & 2011 & 31.3 & 768 & 13.8 \\
\hline Manual work & 481 & 7.5 & 1623 & 29.1 \\
\hline Retired & 230 & 3.6 & 134 & 2.4 \\
\hline Unemployed & 74 & 1.2 & 73 & 1.3 \\
\hline Unknown & 618 & 9.6 & 116 & 2.1 \\
\hline Income & & & & \\
\hline$<£ 20,000$ & 1064 & 16.6 & 552 & 9.9 \\
\hline$£ 20,000-£ 40,000$ & 2282 & 35.5 & 1853 & 33.2 \\
\hline$>£ 40,000$ & 2871 & 44.7 & 3057 & 54.8 \\
\hline Marital Status & & & & \\
\hline Single & 422 & 6.6 & 418 & 7.5 \\
\hline Married/living as married & 3990 & 62.1 & 3605 & 64.7 \\
\hline Widowed/separated/divorced & 567 & 8.8 & 309 & 5.5 \\
\hline Unknown & 1449 & 22.5 & 1242 & 22.3 \\
\hline Smoker Status & & & & \\
\hline Never smoked & 3590 & 55.9 & 2871 & 51.5 \\
\hline Ex smoker & 2061 & 32.1 & 1900 & 34.1 \\
\hline Current smoker & 701 & 10.9 & 742 & 13.3 \\
\hline Site & & & & \\
\hline Cambridge & 2249 & 35.0 & 2096 & 37.6 \\
\hline Ely & 2438 & 37.9 & 1968 & 35.3 \\
\hline Wisbech & 1741 & 27.1 & 1510 & 27.1 \\
\hline PAEE (kJ/day/kg) & 49.7 & 19.6 & 58.8 & 23.0 \\
\hline MVPA in bouts > 1 min (min/day) & 83.4 & 67.2 & 124.0 & 84.7 \\
\hline MVPA in bouts $>10$ min (min/day) & 32.9 & 39.4 & 60.3 & 58.3 \\
\hline Accelerometry $\left(\mathrm{m} / \mathrm{s}^{2}\right)$ & 0.12 & 0.06 & 0.12 & 0.05 \\
\hline
\end{tabular}

Data are mean (SD) or $\mathrm{n}(\%)$ 
Table 2 Multivariable analysis of physical activity by socio-demographic factors in women. The Fenland Study 2005 to 2015

\begin{tabular}{|c|c|c|c|c|c|c|}
\hline & \multicolumn{6}{|c|}{ Women } \\
\hline & \multicolumn{6}{|c|}{$n=6428$} \\
\hline & \multicolumn{2}{|c|}{ PAEE (kJ/day/kg) } & \multicolumn{2}{|c|}{ MVPA in bouts > $1 \mathrm{~min}$ (mins/day) } & \multicolumn{2}{|c|}{ MVPA in bouts $>10 \mathrm{~min}(\mathrm{mins} /$ day } \\
\hline & Mean & 95\% C.I. & Mean & 95\% C.I. & Mean & 95\% C.I. \\
\hline \multicolumn{7}{|l|}{ Age } \\
\hline $29-34$ & Reference & - & Reference & - & Reference & - \\
\hline $35-39$ & -0.5 & $-3.5 ;-2.4$ & 1.6 & $-8.7 ;-11.9$ & 0.6 & $-5.6 ;-6.8$ \\
\hline $40-44$ & $-4.0^{* * *}$ & $-6.8 ;-1.1$ & -5.4 & $-15.4 ; 4.6$ & -3.2 & $-9.2 ; 2.8$ \\
\hline $45-49$ & $-6.0^{* * *}$ & $-8.8 ;-3.1$ & $-8.8^{*}$ & $-18.7 ; 1.2$ & -4.0 & $-10.0 ; 2.0$ \\
\hline $50-54$ & $-8.1^{* * *}$ & $-10.9 ;-5.2$ & $-13.3^{* * *}$ & $-23.2 ;-3.3$ & -4.6 & $-10.6 ; 1.4$ \\
\hline $55-59$ & $-11.0^{* * *}$ & $-13.9 ;-8.1$ & $-21.1^{* * *}$ & $-31.3 ;-10.9$ & $-8.2^{* * *}$ & $-14.3 ;-2.0$ \\
\hline $60-64$ & $-13.8^{* * *}$ & $-17.2 ;-10.4$ & $-23.7^{* * *}$ & $-35.6 ;-11.7$ & $-10.9^{* * *}$ & $-18.1 ;-3.7$ \\
\hline \multicolumn{7}{|l|}{$\mathrm{BMI}$} \\
\hline$<25$ & Reference & - & Reference & - & Reference & - \\
\hline $25-30$ & $-6.2^{* * *}$ & $-7.2 ;-5.2$ & $-20.7^{* * *}$ & $-24.2 ;-17.1$ & $-12.0^{* * *}$ & $-14.1 ;-9.8$ \\
\hline$>30$ & $-14.6^{* * *}$ & $-15.8 ;-13.4$ & $-45.9^{* * *}$ & $-50.0 ;-41.9$ & $-24.1^{* * *}$ & $-26.5 ;-21.6$ \\
\hline \multicolumn{7}{|l|}{ Ethnicity } \\
\hline White & Reference & - & Reference & - & Reference & - \\
\hline South Asian & $-6.4^{* * *}$ & $-10.5 ;-2.3$ & $-18.8^{* *}$ & $-33.2 ;-4.5$ & $-9.9^{* *}$ & $-18.5 ;-1.3$ \\
\hline Black & 0.7 & $-5.7 ; 7.1$ & -1.3 & $-23.6 ; 21.0$ & -0.6 & $-14.0 ; 12.8$ \\
\hline East Asian & $-7.0^{* * *}$ & $-12.3 ;-1.7$ & $-22.6^{* *}$ & $-41.1 ;-4.1$ & $-11.5^{* *}$ & $-22.6 ;-0.4$ \\
\hline Others or unknown & $-4.2^{* * *}$ & $-6.3 ;-2.0$ & $-13.4^{* * *}$ & $-21.0 ;-5.8$ & $-8.8^{* * *}$ & $-13.3 ;-4.2$ \\
\hline \multicolumn{7}{|l|}{ Education level } \\
\hline Basic & Reference & - & Reference & - & Reference & - \\
\hline Further & 0.5 & $-0.6 ; 1.7$ & 0.0 & $-4.0 ; 4.1$ & -0.5 & $-2.9 ; 1.9$ \\
\hline Higher & $1.2^{*}$ & $-0.2 ; 2.6$ & $6.1^{* *}$ & $1.3 ; 10.9$ & $4.3^{* * *}$ & $1.4 ; 7.2$ \\
\hline \multicolumn{7}{|l|}{ Work type } \\
\hline Sedentary & Reference & - & Reference & - & Reference & - \\
\hline Standing & $6.4^{* * *}$ & $5.4 ; 7.5$ & $13.4^{* * *}$ & $9.8 ; 17.0$ & $3.7^{* * *}$ & $1.5 ; 5.8$ \\
\hline Manual work & $13.0^{* * *}$ & $11.3 ; 14.8$ & $38.2^{* * *}$ & $32.1 ; 44.3$ & $17.8^{* * *}$ & $14.2 ; 21.5$ \\
\hline Retired & $3.5^{* * *}$ & $0.9 ; 6.2$ & $11.3^{* *}$ & $2.1 ; 20.6$ & $6.3^{* *}$ & $0.7 ; 11.8$ \\
\hline Unemployed & 0.2 & $-3.9 ; 4.3$ & 2.0 & $-12.4 ; 16.4$ & 1.8 & $-6.8 ; 10.5$ \\
\hline Unknown & $5.0^{* * *}$ & $3.4 ; 6.6$ & $11.3^{* * *}$ & $5.7 ; 16.8$ & $5.3^{* * *}$ & $2.0 ; 8.6$ \\
\hline \multicolumn{7}{|l|}{ Income } \\
\hline$<£ 20,000$ & Reference & - & Reference & - & Reference & - \\
\hline$£ 20,000-£ 40,000$ & $2.8^{* * *}$ & $1.4 ; 4.2$ & $6.7^{* * *}$ & $1.9 ; 11.5$ & $3.1^{* *}$ & $0.3 ; 6.0$ \\
\hline$>£ 40,000$ & $4.5^{* * *}$ & $3.0 ; 5.9$ & $13.0^{* * *}$ & $7.9 ; 18.1$ & $4.2^{* * *}$ & $1.1 ; 7.3$ \\
\hline \multicolumn{7}{|l|}{ Marital Status } \\
\hline Single & Reference & - & Reference & - & Reference & - \\
\hline Married/living as married & -1.4 & $-3.3 ; 0.5$ & $-10.2^{* * *}$ & $-16.8 ;-3.6$ & $-6.4^{* * *}$ & $-10.3 ;-2.5$ \\
\hline Widowed/separated/divorced & -0.4 & $-2.6 ; 1.9$ & -5.3 & $-13.2 ; 2.6$ & $-6.0^{* *}$ & $-10.8 ;-1.3$ \\
\hline Unknown & -0.7 & $-2.7 ; 1.4$ & $-17.6^{* * *}$ & $-24.9 ;-10.3$ & $-6.9^{* * *}$ & $-11.3 ;-2.6$ \\
\hline \multicolumn{7}{|l|}{ Smoker Status } \\
\hline Never smoked & Reference & - & Reference & - & Reference & - \\
\hline Ex smoker & $2.6^{* * *}$ & $1.6 ; 3.6$ & $8.7^{* * *}$ & $5.3 ; 12.1$ & $3.2^{* * *}$ & $1.1 ; 5.2$ \\
\hline
\end{tabular}


Table 2 Multivariable analysis of physical activity by socio-demographic factors in women. The Fenland Study 2005 to 2015 (Continued)

\begin{tabular}{|c|c|c|c|c|c|c|}
\hline Current smoker & $7.9^{* * *}$ & $6.4 ; 9.3$ & $33.5^{* * *}$ & $28.4 ; 38.7$ & $15.8^{* * *}$ & $12.7 ; 18.9$ \\
\hline \multicolumn{7}{|l|}{ Site } \\
\hline Cambridge & Reference & - & Reference & - & Reference & - \\
\hline Ely & $-1.1^{* *}$ & $-2.2 ;-0.0$ & $-5.2^{* * *}$ & $-9.1 ;-1.3$ & $-4.7^{* * *}$ & $-7.0 ;-2.4$ \\
\hline Wisbech & -0.5 & $-1.7 ; 0.8$ & $-4.6^{* *}$ & $-9.0 ;-0.3$ & $-6.6^{* * *}$ & $-9.2 ;-4.0$ \\
\hline \multicolumn{7}{|l|}{ Seasonality } \\
\hline Spring & -0.1 & $-0.7 ; 0.5$ & $1.8^{*}$ & $-0.3 ; 3.9$ & $1.5^{* *}$ & $0.2 ; 2.8$ \\
\hline Winter & $-1.7^{* * *}$ & $-2.3 ;-1.1$ & $-4.8^{* * *}$ & $-7.0 ;-2.6$ & $-1.9^{* * *}$ & $-3.2 ;-0.6$ \\
\hline \multirow[t]{5}{*}{ Constant } & $54.3^{* * *}$ & $50.7 ; 57.8$ & $99.9^{* * *}$ & $87.5 ; 112.4$ & $46.2^{* * *}$ & $38.8 ; 53.7$ \\
\hline & \multicolumn{6}{|c|}{ Men } \\
\hline & \multicolumn{6}{|c|}{$n=5574$} \\
\hline & \multicolumn{2}{|c|}{ PAEE (kJ/day/kg) } & \multicolumn{2}{|c|}{ MVPA in bouts > 1 min (mins/day) } & \multicolumn{2}{|c|}{ MVPA in bouts $>10 \min (\operatorname{mins} /$ day $)$} \\
\hline & Mean & 95\% C.I. & Mean & 95\% C.I. & Mean & 95\% C.I. \\
\hline \multicolumn{7}{|l|}{ Age } \\
\hline $29-34$ & Reference & - & Reference & - & Reference & - \\
\hline $35-39$ & 1.1 & $-2.6 ; 4.7$ & 4.6 & $-9.2 ; 18.5$ & 3.2 & $-6.7 ; 13.1$ \\
\hline $40-44$ & -1.9 & $-5.5 ; 1.7$ & 1.3 & $-12.3 ; 14.9$ & 0.9 & $-8.8 ; 10.6$ \\
\hline $45-49$ & $-5.9^{* * *}$ & $-9.5 ;-2.3$ & -9.1 & $-22.6 ; 4.4$ & -3.7 & $-13.3 ; 6.0$ \\
\hline $50-54$ & $-9.4^{* * *}$ & $-13.0 ;-5.8$ & $-14.6^{* *}$ & $-28.2 ;-1.1$ & -5.3 & $-14.9 ; 4.4$ \\
\hline $55-59$ & $-13.6^{* * *}$ & $-17.3 ;-10.0$ & $-26.8^{* * *}$ & $-40.6 ;-13.0$ & $-12.6^{* *}$ & $-22.5 ;-2.8$ \\
\hline $60-64$ & $-19.1^{* * *}$ & $-23.3 ;-15.0$ & $-37.1^{* * *}$ & $-52.8 ;-21.4$ & $-18.3^{* * *}$ & $-29.5 ;-7.1$ \\
\hline \multicolumn{7}{|l|}{ BMl } \\
\hline$<25$ & Reference & - & Reference & - & Reference & - \\
\hline $25-30$ & $-3.4^{* * *}$ & $-4.7 ;-2.1$ & $-13.9^{* * *}$ & $-18.8 ;-9.1$ & $-12.2^{* * *}$ & $-15.7 ;-8.8$ \\
\hline$>30$ & $-10.1^{* * *}$ & $-11.6 ;-8.5$ & $-41.0^{* * *}$ & $-46.9 ;-35.1$ & $-28.6^{* * *}$ & $-32.8 ;-24.4$ \\
\hline \multicolumn{7}{|l|}{ Ethnicity } \\
\hline White & Reference & - & Reference & - & Reference & - \\
\hline South Asian & $-7.6^{* * *}$ & $-12.3 ;-2.9$ & $-30.3^{* * *}$ & $-48.1 ;-12.6$ & $-19.2^{* * *}$ & $-31.8 ;-6.5$ \\
\hline Black & $-8.9^{* *}$ & $-16.1 ;-1.6$ & $-27.0^{*}$ & $-54.4 ; 0.3$ & -11.5 & $-30.9 ; 8.0$ \\
\hline East Asian & -4.7 & $-13.7 ; 4.3$ & -14.0 & $-48.0 ; 20.0$ & -8.4 & $-32.6 ; 15.9$ \\
\hline Others or unknown & $-3.9^{* * *}$ & $-6.7 ;-1.2$ & $-12.2^{* *}$ & $-22.5 ;-1.9$ & $-8.3^{* *}$ & $-15.6 ;-0.9$ \\
\hline \multicolumn{7}{|l|}{ Education level } \\
\hline Basic & Reference & - & Reference & - & Reference & - \\
\hline Further & -1.3 & $-2.8 ; 0.3$ & $-6.1^{* *}$ & $-11.8 ;-0.3$ & $-4.9^{* *}$ & $-9.0 ;-0.8$ \\
\hline Higher & $-1.7^{*}$ & $-3.5 ; 0.2$ & -5.3 & $-12.3 ; 1.7$ & -1.2 & $-6.2 ; 3.8$ \\
\hline \multicolumn{7}{|l|}{ Work type } \\
\hline Sedentary & Reference & - & Reference & - & Reference & - \\
\hline Standing & $8.5^{* * *}$ & $6.8 ; 10.2$ & $28.2^{* * *}$ & $21.8 ; 34.6$ & $11.1^{* * *}$ & $6.5 ; 15.6$ \\
\hline Manual work & $16.2^{* * *}$ & $14.7 ; 17.6$ & $56.5^{* * *}$ & $51.0 ; 62.0$ & $29.4^{* * *}$ & $25.5 ; 33.3$ \\
\hline Retired & $6.2^{* * *}$ & $2.5 ; 10.0$ & $23.9^{* * *}$ & $9.7 ; 38.0$ & $16.3^{* * *}$ & $6.2 ; 26.4$ \\
\hline Unemployed & 2.9 & $-2.0 ; 7.7$ & 11.7 & $-6.8 ; 30.1$ & 5.7 & $-7.4 ; 18.9$ \\
\hline Unknown & -2.1 & $-6.1 ; 1.9$ & -8.0 & $-23.0 ; 7.0$ & -4.5 & $-15.2 ; 6.2$ \\
\hline
\end{tabular}


Table 2 Multivariable analysis of physical activity by socio-demographic factors in women. The Fenland Study 2005 to 2015 (Continued)

\begin{tabular}{|c|c|c|c|c|c|c|}
\hline \multicolumn{7}{|l|}{ Income } \\
\hline$<£ 20,000$ & Reference & - & Reference & - & Reference & - \\
\hline$£ 20,000-£ 40,000$ & $5.3^{* * *}$ & $3.3 ; 7.4$ & $12.5^{* * *}$ & $4.8 ; 20.2$ & 2.7 & $-2.8 ; 8.2$ \\
\hline$>£ 40,000$ & $7.3^{* * *}$ & $5.2 ; 9.4$ & $21.4^{* * *}$ & $13.4 ; 29.3$ & $8.4^{* * *}$ & $2.7 ; 14.0$ \\
\hline \multicolumn{7}{|l|}{ Marital Status } \\
\hline Single & Reference & - & Reference & - & Reference & - \\
\hline Married/living as married & $2.6^{* *}$ & $0.4 ; 4.8$ & 5.3 & $-2.9 ; 13.5$ & -0.5 & $-6.3 ; 5.4$ \\
\hline Widowed/separated/divorced & $4.1^{* * *}$ & $1.1 ; 7.1$ & $10.7^{*}$ & $-0.8 ; 22.2$ & 0.5 & $-7.7 ; 8.7$ \\
\hline Unknown & 2.0 & $-0.5 ; 4.4$ & -7.6 & $-16.9 ; 1.7$ & -3.9 & $-10.5 ; 2.8$ \\
\hline \multicolumn{7}{|l|}{ Smoker Status } \\
\hline Never smoked & Reference & - & Reference & - & Reference & - \\
\hline Ex smoker & $2.2^{* * *}$ & $1.0 ; 3.4$ & $8.0^{* * *}$ & $3.4 ; 12.5$ & $5.0^{* * *}$ & $1.8 ; 8.2$ \\
\hline Current smoker & $8.7^{* * *}$ & $6.9 ; 10.4$ & $42.3^{* * *}$ & $35.9 ; 48.8$ & $26.2^{* * *}$ & $21.6 ; 30.8$ \\
\hline \multicolumn{7}{|l|}{ Site } \\
\hline Cambridge & Reference & - & Reference & - & Reference & - \\
\hline Ely & 0.1 & $-1.3 ; 1.5$ & -0.9 & $-6.2 ; 4.4$ & -1.8 & $-5.6 ; 1.9$ \\
\hline Wisbech & $2.4^{* * *}$ & $0.9 ; 4.0$ & $8.1^{* * *}$ & $2.1 ; 14.0$ & 1.8 & $-2.4 ; 6.1$ \\
\hline \multicolumn{7}{|l|}{ Seasonality } \\
\hline Spring & $-0.8^{*}$ & $-1.5 ; 0.0$ & -2.4 & $-5.2 ; 0.5$ & -1.3 & $-3.3 ; 0.7$ \\
\hline Winter & $-2.8^{* * *}$ & $-3.5 ;-2.0$ & $-9.8^{* * *}$ & $-12.7 ;-6.9$ & $-6.2^{* * *}$ & $-8.3 ;-4.1$ \\
\hline Constant & $54.4^{* * *}$ & $49.9 ; 59.0$ & $107.5^{* * *}$ & $90.2 ; 124.8$ & $60.9^{* * *}$ & $48.6 ; 73.3$ \\
\hline
\end{tabular}

*** $\mathrm{p}<0.01,{ }^{* *} \mathrm{p}<0.05,{ }^{*} p<0.1$

Fig. 3. Using a 4-MET threshold and 10-min bout definition, only $15 \%$ of women and $31 \%$ of men accumulated the recommended levels of MVPA. Participants accumulated less than half the amount of 10-min bouted MVPA than 1-min bouted MVPA, irrespective of MVPA cutoffs and in both sexes. Using the stricter definition of MVPA, sensitivity analyses of the association with sociodemographic factors (Additional file 1: Table S1) showed largely similar patterns of association to the primary analysis.

\section{Discussion}

In this study we present the descriptive epidemiology of physical activity in a population-sample of UK adults. To our knowledge, this is the first study that describes socio-demographic patterns of both PAEE and its underlying intensity distribution in a large cohort of younger to middle-aged adults.

Our results indicate that men accumulate higher levels of PAEE than women across all ages; a finding consistent with other descriptive studies [7, 21-23]. Men also accumulate higher levels of MVPA and expend more of their energy at higher intensities than women. This may be due to greater household and care-giving activities by women as suggested by others [24] but such domain- specific information was not considered in our study. Despite the energy expenditure differences between men and women as measured by combined sensing, there was no sex difference in movement as measured by accelerometry, as has also been observed in other cohorts [25].

Among both men and women, PA was lower in older individuals. Moreover, the levels and age-associated differences in PAEE demonstrated in Fig. 1 are similar to that recently reported in UK nationally representative samples [7], and the age association remained significant in multivariable analysis (Table 2). Although PAEE and MVPA were highest in young adults, the pattern of association with age was quite different. Whereas PAEE was significantly different between all but the youngest two groups in women and youngest three groups in men, MVPA in $>1$-min bouts was only significantly different between the reference groups and those above 50y $(p<$ 0.05). Furthermore, MVPA in 10-min bouts was only significantly different between the youngest group and the oldest two age groups in both sexes. This finding suggests that intensity patterns of PA may change differently as people age, with LPA replaced by sedentary behaviour proportionally more rapidly than decreases in MVPA.

Normal-weight individuals accumulated higher levels of all activity outcomes than obese individuals. The 


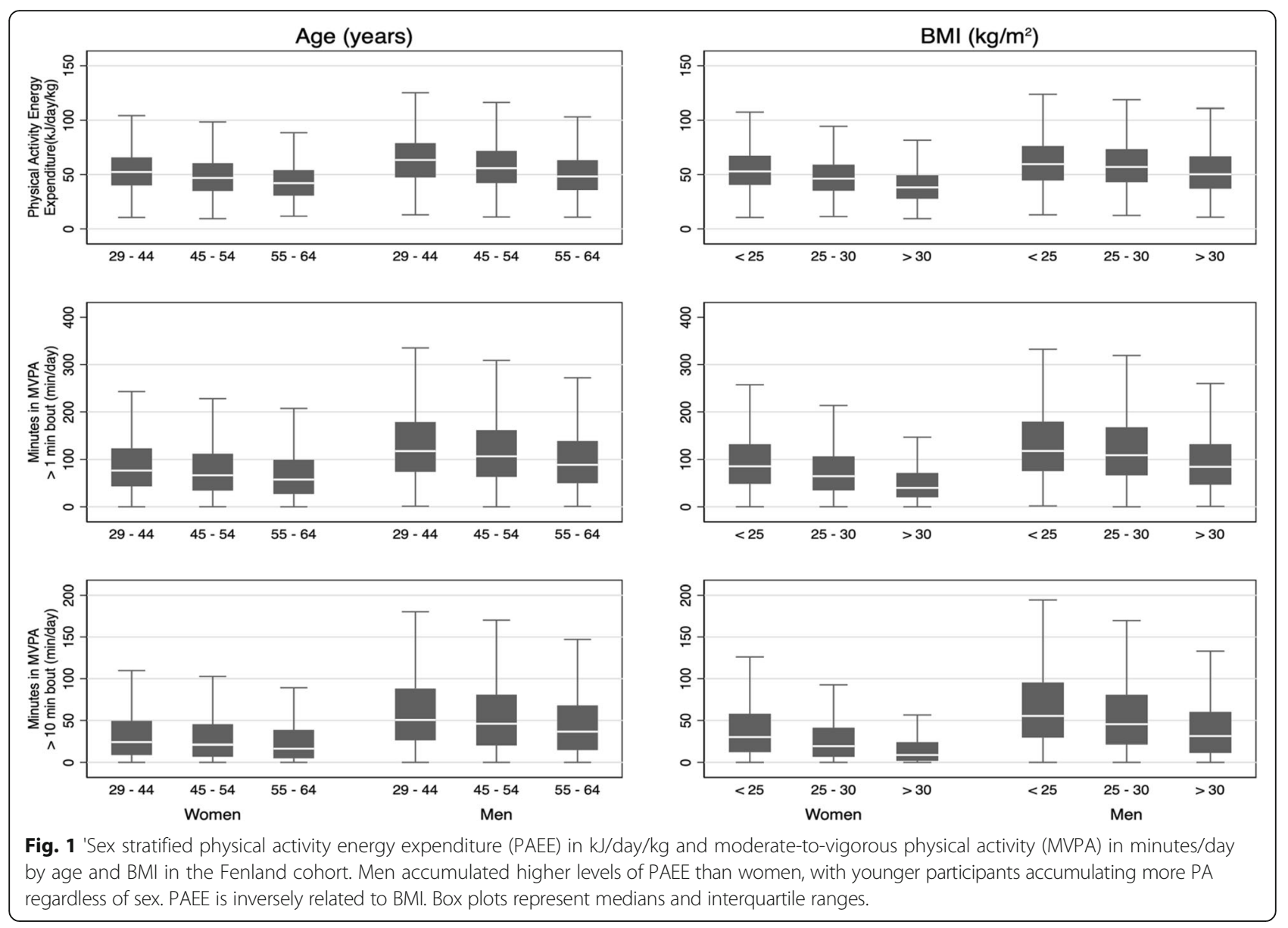

difference in PAEE between normal-weight and obese women was similar to the difference between sedentary and manual workers and between participants in the oldest and youngest age categories. The same comparisons hold true for men. This finding was consistent in a sensitivity analysis for allometrically scaled PAEE (Additional file 1: Table S3), suggesting that obesity is negatively associated with levels of PA in both sexes, irrespective of the effect of body size on absolute energy expenditure as also reported elsewhere [7, 9].

In terms of socio-demographic correlates of PAEE and MVPA, our unadjusted results demonstrated that educational level, income, work type, and smoking status were associated with PAEE and MVPA in women and men. Yet, when mutually adjusted in the multivariable analysis, some of these differences were attenuated. For example, univariable analysis showed a $16 \mathrm{~kJ} \cdot \mathrm{day}^{-1} \cdot \mathrm{kg}^{-1}$ difference between men with sedentary jobs and men with manual jobs. Likewise, univariable analysis modelled a 6 $\mathrm{kJ} \cdot$ day $^{-1} \cdot \mathrm{kg}^{-1}$ difference between men with a basic education compared to those with higher education. When controlled for all sociodemographic covariates, the association between PAEE and education in men decreased in magnitude and significance, whereas the association with different work types remained significant, and of an order of magnitude almost identical to univariable analysis. A similar trend was evident in women. This is due to the strong correlations between certain sociodemographic variables such as lower levels of education and manual work. Conversely, higher levels of education tended to be associated with less PA (in men) but must be balanced against the higher levels of PAEE and MVPA seen with increasing income.

Similarly, the higher attributed levels of PAEE in smokers should be considered in the context of lower chest accelerometry-measured PA in current smokers of both sexes in multivariable analysis (Additional file 1: Table S3). Consistent lower levels of both PAEE and movement were observed in British 60-64yr old smokers [9]. A simple explanation for this apparent discrepancy could be that smokers in the younger Fenland cohort may stand more and sit less, relative to nonsmokers, since standing increases both PAEE and heart rate [26] but the uniaxial accelerometer on the chest would not be able to discriminate sitting and standing still. Smoking is known to increase energy expenditure, independent of movement and resting energy expenditure [27]. Finally, this combination of results may be a partial by-product of the acute increase in heart rate of 

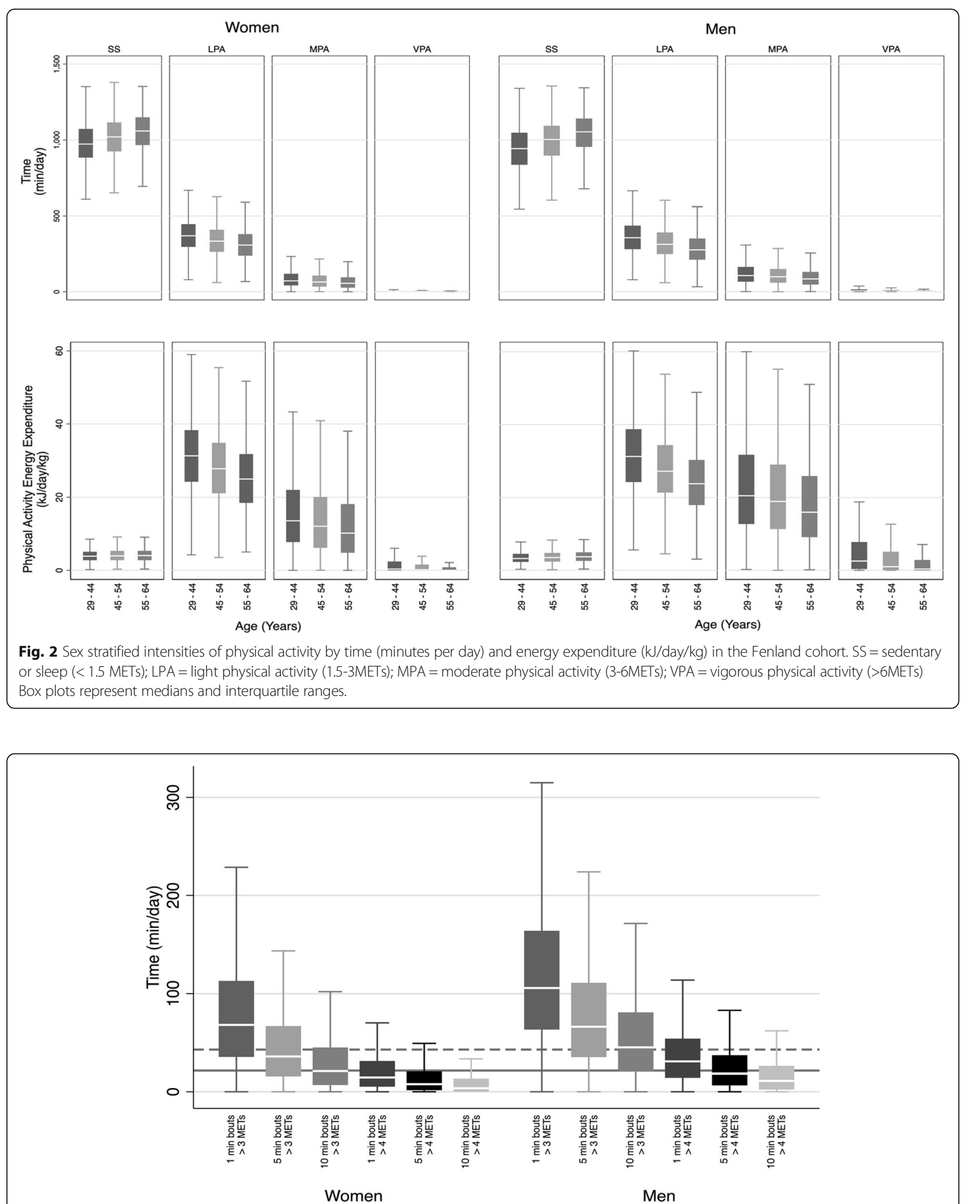

Fig. 3 Sex stratified moderate to vigorous physical activity (MVPA) of differing bout lengths, according to 2 intensity thresholds in the Fenland cohort. The solid grey line indicates compliance with the 2010 UK physical activity guidelines, the dashed line represents double these guidelines. Box plots represent medians and interquartile ranges. 
15 beats/min that has been observed in cigarette smokers [28]. This transient increase in heart rate could have overestimated PAEE derived from the branched model [18].

The levels of PAEE in the Fenland cohort are comparable to those reported in the nationally representative sample of the UK population studied with the goldstandard method of doubly labelled water in NDNS [7]. That study reported mean (SD) PAEE of 52 (20) and 47 (17) $\mathrm{kJ} \cdot \mathrm{day}^{-1} \cdot \mathrm{kg}^{-1}$ in women aged 16-49 and 50-64 respectively. By contrast, men accumulated 63 (23) and 54 (20) $\mathrm{kJ} \cdot \mathrm{day}^{-1} \cdot \mathrm{kg}^{-1}$ in the same age groups. The Cambridge-based ROOTS study reported higher PAEE levels of 84 and $66 \mathrm{~kJ} \cdot \mathrm{day}^{-1} \cdot \mathrm{kg}^{-1}$ in 825,16 -year old boys and girls respectively [8]. By contrast, Golubic et al. reported comparatively lower PAEE levels in the nationally representative 1946 birth cohort of British women and men assessed at age 60-64 years (median (IQR) PAEE: 34 and $36 \mathrm{~kJ} \cdot \mathrm{day}^{-1} \cdot \mathrm{kg}^{-1}$ respectively) [9], suggesting possible regional differences within the UK.

Comparing the Fenland cohort to populations living in locations of differing global developmental indices, we note that various rural cohorts in Africa are more active. However, while men living in urban environments in developing countries have comparable levels of PA to their Cambridgeshire counterparts, women are notably less active. For example, Kenyan men of Kamba, Maasai and Luo ethnic origins had PAEE levels of 81,78 and 74 $\mathrm{kJ} \cdot \mathrm{day}^{-1} \cdot \mathrm{kg}^{-1}$ (age-adjusted to 40 years), respectively [22]. In contrast, Cameroonian and Barbadian urban men recorded comparable levels of PAEE to Fenland men (Cameroon: $52 \mathrm{~kJ} \cdot \mathrm{day}^{-1} \cdot \mathrm{kg}^{-1}, 37$ years old; Barbadian: $47 \mathrm{~kJ} \cdot$ day $^{-1} \cdot \mathrm{kg}^{-1}, 25-54$ years old) whereas Fenland women were more active than the women in those populations (Cameroon: $38 \mathrm{~kJ} \cdot \mathrm{day}^{-1} \cdot \mathrm{kg}^{-1}$, 38 years old; Barbadian: $36 \mathrm{~kJ} \cdot \mathrm{day}^{-1} \cdot \mathrm{kg}^{-1}$, 25-54 years old) [21, 23]. In contrast, DLW-based PAEE estimates in 63-year-old residents from Pittsburg in the US were about 38 $\mathrm{kJ} \cdot \mathrm{day}^{-1} \cdot \mathrm{kg}^{-1}$ in both men and women [29]. This suggests different sex-specific determinants of PAEE in the developed as opposed to the developing world, and rural compared to urbanised environments.

At first glance, the MVPA estimates we report are notably higher than those in accelerometry-based studies [30, 31]. However, if we compare the time spent above the level of chest acceleration commensurate with normal walking on the flat at approximately $3 \operatorname{MET}\left(1 \mathrm{~m} \bullet \mathrm{s}^{-2}\right)$, we capture about half of the total MVPA estimated from the combined sensing method in women and about a third in men (Additional file 1: Table S3); these accelerometerbased estimates are still over twice as high in women and nearly $50 \%$ higher in men compared to similarly defined uniaxial acceleration estimates from NHANES in the US [32]. Although there are also differences in the wear protocols (24-h vs awake-time only), these results suggest real population differences. In both populations, validation work has shown that the underlying walking-running intensity model underpinning this approach of activity assessment underestimates absolute levels, e.g. $18 \%$ bias of DLW-based PAEE in the UK and $24 \%$ in the US $[18,29]$. Others have reported that accelerometry studies calibrated to ambulatory activities may substaintially underestimate time in MVPA [33], and direct validation of the MVPA cut-point used in NHANES show underestimation of MVPA by about $50 \%$, compared to indirect calorimetry during $6 \mathrm{~h}$ of free-living [34]. Given that the intensity estimation from combined sensing compares favourably to both indirect calorimetry and DLW-based PAEE, it is therefore unlikely that the MVPA estimates from the Fenland study are artefactually high $[11,14,16,18]$.

Our study also demonstrates how the intensity and bout definition of MVPA influences the reported prevalence of compliance with physical activity guidelines. At a time when PA guidelines are undergoing review, the difference in the quantity of MVPA accumulated in bouts of at least 1-min duration vs at least 10-min duration is critical. Through the simple abolition of the 10min bouted criterion, apparent compliance rises from 49 to $86 \%$ in women and 74 to $96 \%$ in men (Fig. 3). This difference reflects characterisation according to the new US [4] and UK guidelines [35], as opposed to the 2010 UK guidelines [5]. Furthermore, the new US guidelines emphasise the role of all physical activity in health. Our study suggests that LPA plays a crucial role in the accumulation of overall PAEE, accounting for roughly two thirds of PAEE in women and over half of PAEE in men (Fig. 2). Indeed, without reasonable levels of LPA, it is hard to accumulate high levels of PAEE. Therefore, LPA's role in health should not be underestimated.

Strengths of this study include individually calibrated combined heart rate and movement-based assessment of PAEE and underlying intensity in a large populationbased sample that compares well in terms of PAEE with a nationally representative sample measured by goldstandard measures (i.e. NDNS) [7]. The large sample allowed for detailed description of physical activity by several sociodemographic variables. A further strength is our ability to quantify potential selection bias by comparison of the recruited cohort to the sampling frame population in Cambridgeshire. Whilst this does suggest that the participants are slightly healthier (lower BMI, smoke less, and drink fewer units of alcohol per week) and live in less deprived areas, the differences are small and their likely impact on quantified activity levels not always in the same direction, hence some of the bias will cancel out. Limitations of the study include its lack of representativeness compared to the rest of the UK, in particular the predominance of White participants. 


\section{Conclusions}

In this study we have described the objectively assessed physical activity levels of young to middle-aged adults in the East of England, which are similar to those reported in the nationally representative NDNS study [7]. As with other British studies age, sex and BMI were important correlates of physical activity. We have additionally shown work type, income and smoker status to be associated with MVPA and energy expenditure. Overall, $86 \%$ of women and $96 \%$ of men met the most liberal criteria ( $>3$ METs, $>1 \mathrm{~min}$ bouts) for the PA guidelines, compared to 15 and $31 \%$ respectively for the strictest (> 4 METs, $>10$ min bouts). Uniquely, we have identified LPA as the main driver of PAEE; a component of PA that is currently not quantified as a target in UK guidelines.

\section{Supplementary information}

Supplementary information accompanies this paper at https://doi.org/10. 1186/s12966-019-0882-6.

Additional file 1: Table S1. Comparison of Fenland sampling frame and study subpopulation. The Fenland Study 2005 to 2015. Table S2. Univariable analysis of physical activity by socio-demographic factors in women/men. The Fenland Study. Table S3. Multivariable analysis of socio-demographic factors in women/men using allometric scaling of body weight for PAEE, a higher intensity criterion for MVPA, average trunk acceleration and MVPA defined as trunk acceleration above $1 \mathrm{~m} / \mathrm{s}^{2}$ (equivalent to walking at 3 METs). The Fenland Study 2005 to 2015

Additional file 2: Figure S1. Sex stratified time (minutes per day) across the full spectrum of physical activity intensities in the Fenland cohort. Men accumulated higher levels of very vigorous physical activity than women, although both sexes accumulated relatively little activity over 5 METs. Box plots represent medians and interquartile ranges.

\section{Abbreviations}

BMI: Body mass index; LPA: Light physical activity; MET(s): Metabolic equivalent of task; MPA: Moderate physical activity; MVPA: Moderate-tovigorous physical activity; NDNS: National Diet and Nutrition Survey; PA: Physical activity; PAEE: Physical activity energy expenditure; SS: Sedentary and sleep; VPA: Vigorous physical activity

\section{Acknowledgements}

We are grateful to the Fenland Study participants for their willingness and time to take part. We thank all members of the following teams responsible for practical aspects of the study; Study Coordination, Field Epidemiology, Anthropometry Team, Physical Activity Technical Team, IT, Data Management, and Statistics.

\section{Authors' contributions}

The authors contributed to the present manuscript as follows: Idea for analysis (TL, SB); acquisition, analysis of raw physical activity data (KW, SH, SB): acquisition, analysis of General Practice data (NK, TL), epidemiological data analysis $(\mathrm{TL})$; drafting of the manuscript $(\mathrm{TL})$; revising work critically for important intellectual content (all authors); approval of the final version before submission (all authors). Chief Investigator (NJW) and Principal Investigators (NF, SG, SB) of the Fenland Study.

\section{Funding}

The Fenland study was funded by the Medical Research Council and the Wellcome Trust. The current work was supported by the Medical Research Council (S.B., K.Wi., S.H., grant number MC_UU_12015/3), (S.G., grant number MC_UU_12015/4), (N.K., N.W., grant number MC_UU_12015/1), (N.G.F., grant number MC_UU_12015/5); the National Institute of Health Research
Cambridge (NIHR) Biomedical Research Centre (K.We., S.B., N.G.F., and N.W., grant number IS-BRC-1215-20014); and the Cambridge Trust and St Catharine's College (T.L.). The funders had no role in the design, analysis or writing of this article.

\section{Availability of data and materials}

The datasets generated and analysed during the current study are available at request via the MRC Epidemiology website (http://www.mrc-epid.cam.ac. uk/research/data-sharing/)

\section{Ethics approval and consent to participate}

The participants in the Fenland study were recruited from general practice lists as the population-based sampling frame. The National Research Ethics Service (NRES), the body that approves the ethics of research involving NHS patients, considered and approved the study through its East of England Cambridge Central Committee. All participants provided written informed consent.

\section{Consent for publication}

Not applicable.

Competing interests

The authors declare that they have no competing interests.

Received: 20 August 2019 Accepted: 13 November 2019

Published online: 09 December 2019

\section{References}

1. Lee I-M, Shiroma EJ, Lobelo F, Puska P, Blair SN, Katzmarzyk PT, et al. Effect of physical inactivity on major non-communicable diseases worldwide: an analysis of burden of disease and life expectancy. Lancet. 2012;380:219-29. https://doi.org/10.1016/S0140-6736(12)61031-9.

2. Smith AD, Crippa A, Woodcock J, Brage S. Physical activity and incident type 2 diabetes mellitus: a systematic review and dose-response metaanalysis of prospective cohort studies. Diabetologia. 2016;59:2527-45. https://doi.org/10.1007/s00125-016-4079-0.

3. Hansen A-LS, Carstensen B, Helge JW, Johansen NB, Gram B, Christiansen JS, et al. Combined heart rate- and accelerometer-assessed physical activity energy expenditure and associations with glucose homeostasis markers in a population at high risk of developing diabetes. Diabetes Care. 2013;36: 3062-9. https://doi.org/10.2337/DC12-2671.

4. Piercy KL, Troiano RP, Ballard RM, Carlson SA, Fulton JE, Galuska DA, et al. The physical activity guidelines for Americans. JAMA - J Am Med Assoc. 2018;320:2020-8. https://doi.org/10.1001/jama.2018.14854.

5. Bull FC. The Expert Working Groups Physical Activity Guidelines in the UK: Review and Recommendations Sch Sport Exerc Heal Sci Loughbrgh Univ. 2010. https://doi.org/10.1071/EA03155.

6. Van Remoortel H, Camillo CA, Langer D, Hornikx M, Demeyer H, Burtin C, et al. Moderate intense physical activity depends on selected metabolic equivalent of task (MET) cut-off and type of data analysis. PLoS One. 2013;8: e84365. https://doi.org/10.1371/journal.pone.0084365.

7. Brage $S$, Lindsay $T$, Venables $M$, Wijndaele $K$, Westgate $K$, Collins D, et al. Descriptive epidemiology of energy expenditure in the UK: Findings from the National Diet and Nutrition Survey 2008 to 2015. bioRxiv. 2019:542613. https://doi.org/10.1101/542613.

8. Collings PJ, Wijndaele $\mathrm{K}$, Corder $\mathrm{K}$, Westgate $\mathrm{K}$, Ridgway $\mathrm{CL}$, Dunn V, et al. Levels and patterns of objectively-measured physical activity volume and intensity distribution in UK adolescents: the ROOTS study. Int J Behav Nutr Phys Act. 2014;11:23. https://doi.org/10.1186/14795868-11-23.

9. Golubic R, Martin KR, Ekelund U, Hardy R, Kuh D, Wareham N, et al. Levels of physical activity among a nationally representative sample of people in early old age: results of objective and self-reported assessments. Int J Behav Nutr Phys Act. 2014;11:58. https://doi.org/10. 1186/1479-5868-11-58.

10. Brage S, Brage N, Franks PW, Ekelund U, Wareham NJ. Reliability and validity of the combined heart rate and movement sensor Actiheart. Eur J Clin Nutr. 2005;59:561. https://doi.org/10.1038/sj.ejcn.1602118.

11. Brage $S$, Ekelund U, Brage N, Hennings MA, Froberg K, Franks PW, et al. Hierarchy of individual calibration levels for heart rate and accelerometry to 
measure physical activity. J Appl Physiol. 2007;103:682-92. https://doi.org/10. 1152/japplphysiol.00092.2006.

12. Tanaka H, Monahan KD, Seals DR. Age-predicted maximal heart rate revisited. J Am Coll Cardiol. 2001:37:153-6. https://doi.org/10.1016/507351097(00)01054-8

13. Stegle O, Fallert SV, Mackay DJC, Brage S. Gaussian process robust regression for noisy heart rate data. IEEE Trans Biomed Eng. 2008;55:214351. https://doi.org/10.1109/TBME.2008.923118.

14. Brage S, Brage N, Franks PW, Ekelund U, Wong MY, Andersen LB, et al. Branched equation modeling of simultaneous accelerometry and heart rate monitoring improves estimate of directly measured physical activity energy expenditure. J Appl Physiol. 2004;96:343-51. https://doi.org/10.1152/ japplphysiol.00703.2003.

15. Strath SJ, Brage S, Ekelund U. Integration of physiological and accelerometer data to improve physical activity assessment. In: Medicine and Science in Sports and Exercise; 2005. p. S563-71. https://doi.org/10.1249/01.mss. $0000185650.68232 .3 f$

16. Thompson D, Batterham AM, Bock S, Robson C, Stokes K. Assessment of low-to-moderate intensity physical activity thermogenesis in young adults using synchronized heart rate and Accelerometry with branched-equation modeling. J Nutr. 2006;136:1037-42. https://doi.org/10.1093/jn/136.4.1037.

17. Brage S, Westgate K, Wijndaele K, Godinho J, Griffin S, Wareham N. Evaluation of a method for minimising diurnal information bias in objective sensor data. In: ICAMPAM (Amherst):; 2013.

18. Brage S, Westgate K, Franks PW, Stegle O, Wright A, Ekelund U, et al. Estimation of free-living energy expenditure by heart rate and movement sensing: a doubly-labelled water study. PLoS One. 2015;10:1-19. https://doi. org/10.1371/journal.pone.0137206.

19. White $C R$, Seymour RS. Allometric scaling of mammalian metabolism. J Exp Biol. 2005;208:1611-9. https://doi.org/10.1242/jeb.01501.

20. Sarrus M, Rameaux J. Rapport sur un memoire adresse a l'academie royale de medicine. Bull I'Academie R Med. 1838;3:1094-100 http://ci.nii.ac.jp/ naid/10025722524/en/. .

21. Assah F, Mbanya JC, Ekelund U, Wareham N, Brage S. Patterns and correlates of objectively measured free-living physical activity in adults in rural and urban Cameroon. J Epidemiol Community Health. 2015;69:700-7. https://doi.org/10.1136/JECH-2014-205154.

22. Christensen DL, Faurholt-Jepsen D, Boit MK, Mwaniki DL, Kilonzo B, Tetens I, et al. Cardiorespiratory fitness and physical activity in Luo, Kamba, and Maasai of rural Kenya. Am J Hum Biol. 2012;24:723-9. https://doi.org/10.1002/ajhb.22303.

23. Howitt C, Brage S, Hambleton IR, Westgate K, Samuels TA, Rose AM, et al. A cross-sectional study of physical activity and sedentary behaviours in a Caribbean population: combining objective and questionnaire data to guide future interventions energy balance-related behaviors. BMC Public Health. 2016;16:1-12. https://doi.org/10.1186/s12889-016-3689-2.

24. Matthews CE, Berrigan D, Fischer B, Gomersall SR, Hillreiner A, Kim Y, et al. Use of previous-day recalls of physical activity and sedentary behavior in epidemiologic studies: results from four instruments. BMC Public Health. 2019:19:478. https://doi.org/10.1186/s12889-019-6763-8

25. Doherty A, Jackson D, Hammerla N, Plötz T, Olivier P, Granat MH, et al. Large scale population assessment of physical activity using wrist worn accelerometers: the UK biobank study. PLoS One. 2017;12:1-14.

26. Miles-Chan JL, Sarafian D, Montani JP, Schutz Y, Dulloo A. Heterogeneity in the energy cost of posture maintenance during standing relative to sitting: Phenotyping according to magnitude and time-course. PLoS One. 2013;8. https://doi.org/10.1371/journal.pone.0065827.

27. Hofstetter A, Schutz Y, Jéquier E, Wahren J. Increased 24-hour energy expenditure in cigarette smokers. N Engl J Med. 1986;314:79-82. https://doi. org/10.1056/NEJM198601093140204.

28. Houlihan ME, Pritchard WS, Robinson JH. A double blind study of the effects of smoking on heart rate: is there tachyphylaxis? Psychopharmacology. 1999;144: 38-44. https://doi.org/10.1007/s002130050974.

29. Matthews CE, Keadle SK, Moore SC, Schoeller DS, Carroll RJ, Troiano RP, et al. Measurement of active and sedentary behavior in context of large epidemiologic studies. Med Sci Sports Exerc. 2018;50:266-76. https://doi. org/10.1249/MSS.0000000000001428.

30. Troiano RP, Berrigan D, Dodd KW, Mâsse LC, Tilert T, Mcdowell M. Physical activity in the United States measured by accelerometer. Med Sci Sports Exerc. 2008;40:181-8.

31. Berkemeyer K, Wijndaele K, White T, Cooper AJM, Luben R, Westgate K, et al. The descriptive epidemiology of accelerometer-measured physical activity in older adults. Int J Behav Nutr Phys Act. 2016;13:2. https://doi.org/ 10.1186/s12966-015-0316-Z

32. Wolff-Hughes DL, Fitzhugh EC, Bassett DR, Churilla JR. Waist-worn actigraphy: population-referenced percentiles for total activity counts in U.S. adults. J Phys Act Health. 2015;12:447-53.

33. Matthews CE, Keadle SK, Berrigan D, Staudenmayer J, F Saint-Maurice P, Troiano RP, et al. Influence of Accelerometer Calibration Approach on Moderate-Vigorous Physical Activity Estimates for Adults. Med Sci Sports Exerc. 2018;50:2285-91. https://doi.org/10.1249/MSS.0000000000001691.

34. Crouter SE, DellaValle DM, Haas JD, Frongillo EA, Bassett DR. Validity of actigraph 2-regression model, Matthews cut-points, and nhanes cut-points for assessing free-living physical activity. J Phys Act Health. 2013;10:504-14.

35. UK Chief Medical Officers. UK Chief Medical Officers ' physical activity guidelines. 2019. https://www.gov.uk/government/publications/physicalactivity-guidelines-uk-chief-medical-officers-report. Accessed 5 Nov 2019.

\section{Publisher's Note}

Springer Nature remains neutral with regard to jurisdictional claims in published maps and institutional affiliations.

Ready to submit your research? Choose BMC and benefit from:

- fast, convenient online submission

- thorough peer review by experienced researchers in your field

- rapid publication on acceptance

- support for research data, including large and complex data types

- gold Open Access which fosters wider collaboration and increased citations

- maximum visibility for your research: over $100 \mathrm{M}$ website views per year

At $\mathrm{BMC}$, research is always in progress.

Learn more biomedcentral.com/submissions 